\title{
O Conceito de Biossegurança à Luz da Ciência Pós-Normal: avanços e perspectivas para a saúde coletiva
}

\section{The Concept of Biosafety in Light of Post-Normal Science: advancements and perspectives to collective health}

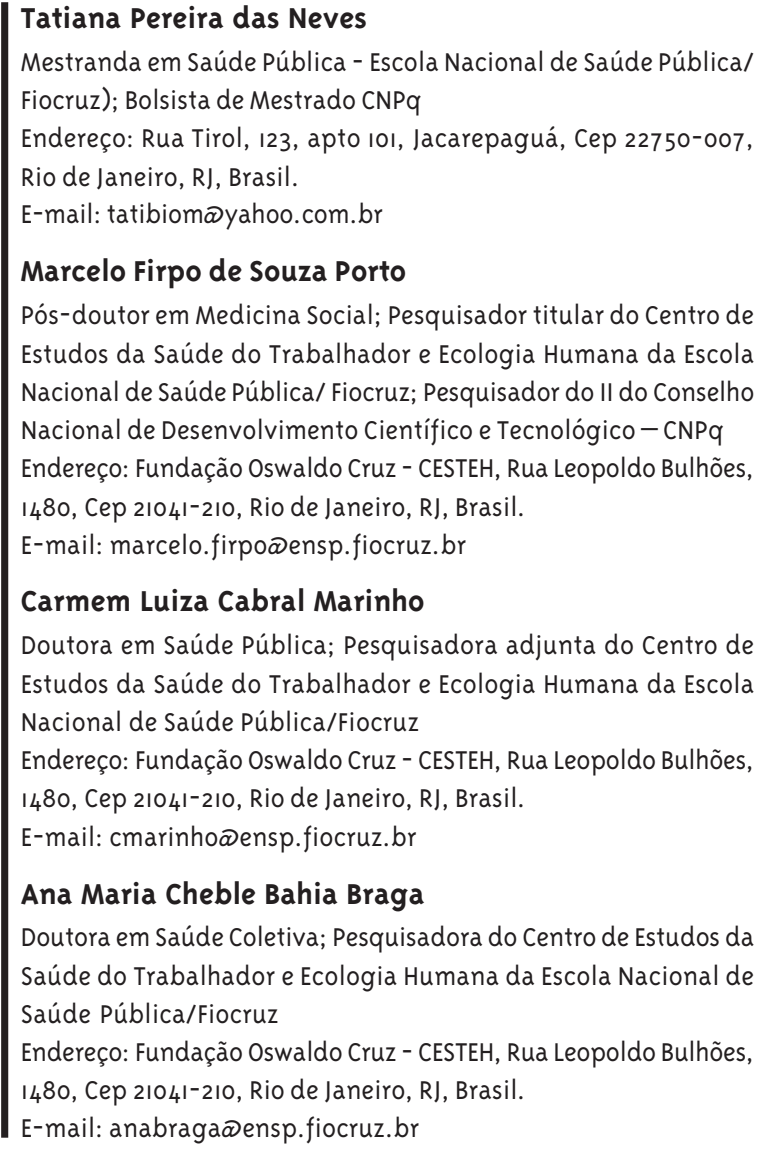

\section{Ana Maria Cheble Bahia Braga}

Doutora em Saúde Coletiva; Pesquisadora do Centro de Estudos da Saúde do Trabalhador e Ecologia Humana da Escola Nacional de Saúde Pública/Fiocruz

Endereço: Fundação Oswaldo Cruz - CESTEH, Rua Leopoldo Bulhões, 1480, Cep 21041-210, Rio de Janeiro, RJ, Brasil.

E-mail: anabragaळensp.fiocruz.br

\section{Resumo}

Trata-se de um estudo de natureza teórico-conceitual, que analisa as limitações do conceito de biossegurança à luz da ciência pós-normal, buscando contribuir para o debate sobre as controvérsias associadas à biossegurança. Parte do pressuposto que a noção de biossegurança, ao basear-se em uma abordagem eminentemente tecnicista do risco, não responde de maneira satisfatória às questões que se apresentam. Sendo o principal propósito da biossegurança proteger a saúde e o meio ambiente, torna-se necessária uma mudança da perspectiva reducionista da ciência tradicional, na qual a noção de biossegurança foi concebida. Essa mudança deve ocorrer dentro de uma abordagem ampla, que destaque as noções de incerteza, complexidade e qualidade, assim como considerar a pluralidade de atores e interesses envolvidos nos complexos problemas ambientais e de saúde. Conclui-se que conceber a noção de biossegurança à luz da ciência pós-normal implica uma modificação fundamental, principalmente em relação à saúde coletiva: a substituição do discurso tecnicista onipotente por um diálogo entre os diversos atores sociais envolvidos nas questões ambientais e de saúde.

Palavras-chave: Biossegurança; Ciência Pós-Normal; Saúde Coletiva. 


\section{Abstract}

This is a theoretical-conceptual study that aims to analyse the limitations of the concept of biosafety in light of post-normal science. It intends to contribute to the discussion about the controversies that are associated with biosafety. The presupposition is that the notion of biosafety relies on a technicist approach to risk that does not answer properly the current questions. As the main purpose of biosafety is to protect health and the environment, it is necessary to replace the reductionist perspective of traditional science, in which the notion of biosafety was conceived, by a wide approach: post-normal science. This perspective emphasizes the notions of uncertainty, complexity and quality and takes into account the plurality of social actors and interests involved in the complex environmental and health problems. The study concludes that understanding the concept of biosafety in light of post-normal science implies a fundamental modification, mainly regarding collective health: the substitution of a technicist omnipotent discourse for a dialogue between the different social actors involved in the environmental and health questions.

Keywords: Biosafety; Post-Normal Science; Collective Health.

\section{Introdução}

Diversas definições para biossegurança encontramse descritas na literatura, entretanto, para este estudo foi adotada a definição da Comissão Técnica Nacional de Biossegurança (CTNBio): "processo voltado para a segurança, o controle e a diminuição de riscos advindos da biotecnologia"

Este estudo parte do pressuposto, conforme Glover (2003), de que o conceito de biossegurança implica uma abordagem técnico-científica do risco, segundo a qual, o risco é entendido como "uma realidade objetiva, que pode ser medida, controlada e gerenciada" (Althaus, 2005, p.572), de maneira exclusivamente científica (Wynne, 2001). Serão discutidas, assim, as limitações desse tipo de abordagem e como esse enfoque suscita discussões e conflitos entre os diversos atores sociais envolvidos (Borch e Rasmussen, 2005).

O conceito de ciência pós-normal foi desenvolvido em resposta às novas condições da ciência no contexto social, em que há crescente incerteza e turbulência diante do agravamento e do aumento da complexidade dos problemas ambientais contemporâneos (Ravetz, 1999). Assume-se que a ciência normal, no sentido dado por Thomas Kuhn (1987), em seu livro A Estrutura das Revoluções Científicas, não consegue fornecer respostas adequadas para problemas marcados por elevadas incertezas, múltiplos interesses e valores em jogo, e que demandam ações de curto prazo para o seu enfrentamento. Nesses casos, a abordagem da ciência pósnormal seria recomendada, sendo caracterizada pela busca de uma interação mais ativa entre ciência, ética e política (rompendo a dicotomia entre ciência hard e soft), entre conhecimento e ignorância (situação na qual não se sabe nem o que não se sabe). Na perspectiva da ciência pós-normal são aceitos outros enfoques além dos científicos, através da comunidade estendida de pares, na qual o saber e a participação dos trabalhadores e das comunidades são efetivamente considerados (Porto e Freitas, 1997).

Embora aparentemente seja paradoxal articular biossegurança e ciência pós-normal, pois são noções que em uma primeira leitura podem sugerir oposição,

1 COMISSÃO TÉCNICA NACIONAL DE BIOSSEGURANÇA. Utilitários. Disponível em: <http://www.ctnbio.gov.br〉. Acesso em: 8 dez. 2005. 
este estudo pretende demonstrar a aproximação dessas duas idéias, buscando contribuir com a reflexão acerca dos conflitos em torno da regulação da biotecnologia.

Assim, este estudo discute o conceito de biossegurança a partir da perspectiva da ciência pós-normal, refletindo sobre os possíveis avanços conceituais possibilitados por essa abordagem. Busca ainda, analisar as limitações da concepção tradicional e suas implicações, além de procurar integrar esse conceito com a ciência pós-normal, a fim de contribuir com o debate sobre a regulação das novas tecnologias. Pretende, assim, indicar processos decisórios mais democráticos, como a elaboração de estratégias que contribuam no sentido de superar as controvérsias sobre possíveis problemas ambientais e de saúde que os organismos geneticamente modificados possam ocasionar. Segundo Freitas (2003), os problemas ambientais devem ser compreendidos também como problemas de saúde, uma vez que atingem os seres humanos e as sociedades de maneira múltipla e simultânea.

Para isso, este artigo foi desenvolvido da seguinte maneira: na segunda parte aprofunda-se o conceito de biossegurança, em seguida são analisadas as contribuições provenientes da proposta da ciência pós-normal, e, finalmente, discute a integração da perspectiva da ciência pós-normal com a noção de biossegurança.

\section{Reflexões sobre o Conceito de Biossegurança}

Durante a década de 1970, o governo norte-americano respondeu ao ativismo político e social iniciado na década anterior de várias formas, e nesse contexto surgiu a regulação governamental, que procurou proteger trabalhadores e o meio ambiente dos possíveis riscos advindos do avanço tecnológico. A Conferência de Asilomar surgiu, assim, como uma tentativa de discutir e apresentar propostas para minimizar e controlar os riscos do progresso científico (Krimsky, 2005).

Essa conferência, considerada um importante marco na construção do conceito de biossegurança, reuniu em 1975, nos Estados Unidos, os principais especialistas da época para discutir maneiras de lidar com os potenciais riscos envolvidos na pesquisa do DNA recombinante, técnica principal da biologia molecular. Ainda que o relatório resultante não inclua a expressão biossegurança (Berg e col., 1975), é possível afir- mar que a lógica de construção deste conceito tenha surgido nesse encontro. Essa afirmação baseia-se na inclusão de aspectos de proteção, que tinham como objetivo minimizar os possíveis riscos que a técnica do DNA recombinante poderia oferecer aos trabalhadores em laboratórios, ao público em geral e ao ambiente (Cerezo e Luján, 200o).

Vale destacar que a Conferência de Asilomar foi um grande esforço para antecipar, avaliar e reduzir cientificamente os potenciais riscos oferecidos pela técnica do DNA recombinante. Contudo, a tentativa de auto-regulação dessa reunião limitou a participação aos cientistas, excluindo outros atores sociais, gerando, assim, controvérsias públicas que culminaram em sérias implicações sociais (Weiner, 2001). É possível afirmar que essa limitação à participação dos diversos atores sociais teve implicações importantes na elaboração do conceito de biossegurança (Glover, 2003).

Assim, a noção de biossegurança foi concebida e adotada por grupos de elite e organizações de especialistas tecnocráticos intensamente isolados dos interesses e das pressões sociais e funciona como um modelo normativo para a regulação da biotecnologia (Glover, 2003).

O princípio básico da biossegurança é a avaliação científica dos riscos (Cardoso e col., 2005), metodologia que foi sumarizada por Hill e colaboradores (2004) da seguinte forma:

- identificação das características que possam apresentar efeitos adversos (identificação do risco);

- avaliação da probabilidade dos efeitos (ou outra medida de exposição);

- avaliação das conseqüências dos mencionados efeitos, caso ocorram;

- caracterização do risco baseado na probabilidade e nas conseqüências dos efeitos (caracterização dos riscos).

Observa-se que o conceito de biossegurança é fundamentado na premissa de que os riscos podem ser identificados, avaliados e controlados pela ciência (Wynne, 2001). Além disso, sugere uma separação entre ética e risco, na qual cientistas e reguladores são designados para lidar com assuntos relacionados ao risco, enquanto os interesses sociais são considerados separadamente, freqüentemente denominados “assuntos éticos”, delegados à avaliação por especialistas em ética (Levidow, 2001). 
Essa "fronteira" entre risco e ética, com a qual a noção de biossegurança opera, é estratégica, pois por ela buscou-se conquistar credibilidade à avaliação dos especialistas: tanto dos reguladores em assuntos de segurança como dos profissionais em ética (Levidow, 2001).

Apesar da noção de biossegurança ser tipicamente fundamentada na abordagem científica do risco, questões primordiais sobre os riscos não são respondidas por essa perspectiva (Mulligan, 200o). Desse modo, o conceito de biossegurança deve ser compreendido como uma base que estrutura implicações e seleciona aquelas que sejam relevantes em relação ao enfoque regulatório, dentro de limites bem definidos (Glover, 2003).

A polêmica associada à biossegurança freqüentemente relaciona-se ao debate "riscos versus benefícios", no qual os defensores da biotecnologia destacam os benefícios dos organismos geneticamente modificados, enquanto seus opositores procuram mostrar os possíveis impactos negativos. No entanto, esse debate é baseado em um discurso controverso: enquanto os riscos são apresentados como probabilidades, oculta-se que os chamados "benefícios" também são possibilidades, ou seja, apenas possíveis benefícios (Mulligan , 200o). Além disso, também omite-se estrategicamente a propósito de que esses riscos devem ser assumidos e enfrentados (Wynne, 2001).

\section{A Proposta da Ciência Pós-Normal}

A ciência pós-normal é um enfoque alternativo sobre a ciência tradicional, que se encontra em fase inicial de desenvolvimento, localizando-se na interface entre ciência e sociedade, promovendo a investigação com precaução, uma vez que seu maior interesse é a reação diante dos efeitos negativos não-intencionais do progresso (De Marchi e Funtocowicz, 2004).

Trata-se, assim, de uma nova concepção sobre o gerenciamento dos complexos problemas relacionados à ciência e centrada em aspectos que as práticas racionais científicas tendem a desprezar: incertezas, peso dos valores e pluralidade de perspectivas legítimas (De Marchi e Funtocowicz, 20004).

A noção da ciência como pós-normal proporciona um contraponto à normalidade, que pode ter dois significados. 0 primeiro é a pesquisa científica como normalidade kuhniana, na qual a prática científica eficaz seria a resolução de um "quebra-cabeça" dentro de um paradigma que tende a ignorar questões mais amplas, como a complexidade, a incerteza, a diversidade e a multiplicidade dos fatos e dos interesses legítimos em jogo (Palmas e Mattos, 2001). O segundo é a premissa de que a política ambiental é "normal", ou seja, a solução rotineira dos problemas por parte dos especialistas busca uma base de conhecimento suficiente para as decisões políticas (Ravetz, 1999).

A ciência tradicional, denominada normal, embora seja capaz de solucionar problemas simples ou problemas de "complexidade desorganizada", não responde adequadamente àqueles de "complexidade organizada”. Um sistema simples pode ser compreendido usando uma perspectiva simples e um modelo padrão analítico, que forneça uma descrição satisfatória ou soluções gerais por meio de operações de rotina (Gallopín e col., 2001). Eles correspondem aos sistemas fisicalistas clássicos, cuja operacionalização se deu por várias engenharias que estão na base do desenvolvimento tecnológico dos últimos dois séculos. Já aqueles de "complexidade desorganizada" ou "ordinária" compreendem uma diversidade de elementos e subsistemas que interagem e se complementam, produzindo fenômenos como feedbacks (retroalimentação) e mudanças de fase. Este tipo de sistema possui uma maior indeterminância e é típico dos sistemas biológicos não humanos: neles há uma ausência da autoconsciência e de propósitos mais completos por parte dos seres vivos, com um padrão de organização voltado para a complementaridade de competências e de cooperação, como a predação, o parasitismo e a simbiose, sendo, dessa forma, a estabilidade do sistema mantida contra as perturbações intervenientes. Finalmente, a "complexidade organizada", ou "emergente" é típica dos sistemas sociais, técnicos ou mistos que incluem os seres humanos, possuindo características como intencionalidade, consciência, representações simbólicas e moralidade. Constitui-se em um sistema que não pode ter seu mecanismo de funcionamento completamente explicado, pois para sua análise é necessário um pensamento dialético, no qual a contradição é um conceito chave (Palmas e Mattos, 2001).

Essa inadequação da ciência normal em solucionar problemas de "complexidade organizada" ou "emergente" pode ser identificada na regulação dos orga- 
nismos geneticamente modificados, em que as incertezas ambientais são freqüentemente ignoradas (Gallopín e col., 2001).

É importante compreender as diferenças existentes entre os vários tipos de incerteza, pelos conceitos de risco, indeterminância e ignorância. De acordo com Giampietro (2002), o conceito de risco aplica-se a situações nas quais é possível estabelecer uma distribuição de probabilidades para um dado conjunto de possíveis conseqüências e há modelos válidos para prever e representar o que irá ocorrer em um ponto particular no tempo e no espaço. Já a indeterminância aplica-se a situações em que não é possível prever com exatidão o que irá acontecer. 0 problema da incerteza aqui decorre não da falta de modelos nem de infra-estrutura, mas da existência de fenômenos com múltiplos elementos, processos não-lineares e feedbacks operando em distintas escalas espaciais e temporais, que dificultam previsões precisas. Um exemplo clássico é o da previsão do tempo numa cidade ou região dentro de algumas semanas.

A incerteza de nível mais elevado é a ignorância, decorrente de situações tão complexas que a ciência sequer possui modelos adequados para predizer e atribuir os cenários futuros mais relevantes. A ignorância pode ser dividida em ignorância redutível e ignorância irredutível. A ignorância redutível pode ser solucionada pela realização de investigações científicas posteriores, enquanto a irredutível não pode ser resolvida por futuras pesquisas e estudos, pois tais investigações não fornecem conhecimento suficiente sobre interações fundamentais que marcam o indeterminismo e a imprevisibilidade do sistema (Walker e col., 2003).

As clássicas abordagens compartimentalizadas da ciência vêm provocando o agravamento dos problemas ambientais, ao não considerar o intrínseco indeterminismo dos sistemas complexos dinâmicos, que envolvem tanto o mundo natural como as interferências humanas no ambiente. Definir complexidade não é uma tarefa simples, existem diferentes concepções sobre ela. É importante ressaltar que o aumento do número de elementos e/ou relações em um sistema não resulta necessariamente em complexidade. Sistemas complexos geralmente exibem características que os tornam mais difíceis de compreender e de gerenciar que sistemas complicados e simples. Essas característi- cas podem ser resumidas, de acordo com Gallopín e colaboradores (2001), pelas seguintes características: pluralidade de perspectivas legítimas, não-linearidade, emergência, organização própria, multiplicidade de escalas e incerteza irredutível.

O processo de descoberta de soluções criativas para situações complexas requer respeito pelas perspectivas e pelos interesses dos componentes da comunidade estendida de pares, pois nesse processo a verdade deve ser construída por diálogos e pela produção de compromissos. Assim, a qualidade da análise dos problemas e das soluções encaminhadas depende da revisão estendida dos pares para ser realizada com êxito, pois o processo da ciência pós-normal é de aprendizagem mútua. Além disso, pode-se afirmar que uma das grandes lições da ciência pós-normal é ressaltar que a qualidade dos resultados não depende da eliminação da incerteza, mas do adequado gerenciamento dela pelo reconhecimento dos diversos pontos de vista dos atores sociais envolvidos (Ravetz, 2004).

Tradicionalmente, acreditava-se que a ciência avançava de modo contínuo, conhecendo e controlando a natureza progressivamente. No entanto, atualmente a ciência está em confronto com complexidades, lidando com incertezas e enfrentando decisões tecnológicas e ambientais urgentes, local e globalmente. Nesse contexto científico novo e mais amplo o controle da qualidade dos resultados da pesquisa não pode mais ser delegado a comunidades isoladas de especialistas, uma vez que precisa ser renovado e enriquecido. Nesse sentido, a originalidade da ciência pós-normal consiste justamente em enfatizar o que foi desprezado pela ciência normal, ou seja, destacar as noções de incerteza, complexidade e qualidade (Funtocowicz e Ravetz, 1997).

As abordagens científicas clássicas concebem o progresso científico e tecnológico sempre como proveitosos, considerando os malefícios menores e circunstanciais, uma vez que o próprio desenvolvimento científico e tecnológico iria sempre, gradualmente, reduzir as incertezas ao nível de riscos, que podem ser avaliados e controlados (Porto, 2005).

Deve-se considerar que a moderna ciência experimental fundamenta-se, boa parte, na concepção de que o sistema sob investigação é relativamente estável, possibilitando a previsibilidade de comportamentos futuros com algum grau de certeza (Clark e col., 2002). 
Além disso, a organização histórico-institucional da ciência foi baseada na fragmentação do objeto que, juntamente com a crescente especialização do sujeito científico, constituiu a disciplinaridade (Almeida-Filho, 1998).

No entanto, os problemas de saúde e ambientais podem ser compreendidos como exemplos de objetos complexos, pois envolvem simultaneamente o meio físico-biológico, a produção, a organização social, a economia e a cultura, que interagem com seres humanos e ecossistemas, podendo, assim, adquirir características de maior vulnerabilidade ou mais saúde diante dos riscos. Analisar de maneira fragmentada qualquer dessas dimensões, como é a proposta da ciência normal, pode suscitar problemas analíticos e éticos, gerando, desta maneira, propostas de soluções limitadas (Porto e Almeida, 2002).

A abordagem da ciência pós-normal, no entanto, não deve ser considerada um ataque ao trabalho dos especialistas ou a sua eliminação, e sim um auxílio à ciência normal, que tem espaço em qualquer estudo ambiental, mas precisa ser complementada pela consciência da natureza pós-normal dos problemas ambientais. Para a perspectiva da ciência pós-normal, o papel da ciência é essencial, embora deva ser apreciado no contexto das incertezas dos sistemas naturais, em relação à relevância aos valores humanos, considerando-se a complexidade dos problemas e a correspondente complexidade do conhecimento (Ravetz, 1999).

\section{O Conceito de Biossegurança e a Ciência Pós-Normal: um diálogo possivel?}

Como discutido anteriormente, o conceito de biossegurança implica uma abordagem técnico-científica do risco (Glover, 2003). A natureza e o significado do risco, entretanto, não podem ser compreendidos completamente utilizando-se somente as ferramentas técnico-científicas da ciência normal, pois o seu significado emerge e se modifica no curso do debate político e social. Os riscos são complexos e orgânicos, contudo a tradicional estruturação técnico-científica dos riscos pode ser considerada uma estratégia de despolitização dos debates que resulta em um mecanismo de exclusão. Tal mecanismo traduz alguns interesses como próprios (científicos) e o outros como impróprios (dos demais atores sociais) (Wales e Mythen, 2002).

O discurso clássico da ciência, fundamento da noção de biossegurança, regula a produção de "verdade", ou seja, a visão tradicional da ciência estabelece um domínio no qual a prática do verdadeiro e do falso pode ser ordenada de maneira estratégica (Wales e Mythen, 2002). Na perspectiva da ciência pós-normal, busca-se que a verdade seja construída em um processo de aprendizagem mútuo entre os diferentes atores sociais, no qual os interesses e os valores das partes envolvidas sejam considerados e respeitados igualmente (Ravetz, 2004).

A concepção tradicional de biossegurança, tendo por princípio basilar a avaliação científica, também implica crer na previsibilidade dos fenômenos que são definidos como riscos (Glover, 2003). No entanto, problemas de saúde e ambientais são complexos, muito difíceis de prever com grau razoável de certeza, além de apresentarem uma pluralidade de perspectivas legítimas dos diferentes atores sociais (Gallopín e col., 2001), pois "não há uma definição correta para risco e os entendimentos existentes são mutáveis no decorrer do debate político e social" (Wales e Mythen, 2002, p.139).

Pode-se afirmar que a incorporação dos pressupostos da ciência pós-normal à noção de biossegurança poderá contribuir de forma significativa, pois se "o processo voltado para a segurança, o controle e a diminuição de riscos advindos da biotecnologia" ${ }^{1}$ tiver o real propósito de proteger a saúde humana e ambiental, torna-se fundamental que se proponha a pesquisa científica com precaução.

Weed (2004) argumenta que o objetivo da precaução é o mesmo da própria saúde coletiva, isto é, efetuar ações preventivas com a finalidade de reduzir doenças, danos e mortes prematuras. Entretanto, apesar dos conceitos de precaução e de prevenção serem muitas vezes utilizados indistintamente, uma análise mais aprofundada revelará que os referidos conceitos não são sinônimos (Sandin, 2004). A distinção entre

I COMISSÃO TÉCNICA NACIONAL DE BIOSSEGURANÇA. Utilitários. Disponível em: <http://www.ctnbio.gov.br>. Acesso em: 8 dez. 2005 . 
problemas estruturados e desestruturados ajuda a esclarecer a diferença entre tais conceitos, uma vez que a prevenção é aplicada a problemas estruturados e a precaução consiste em uma abordagem utilizada para problemas desestruturados em que o nível da complexidade e das incertezas envolvidas é muito elevado. Existem ainda formas intermediárias - problemas mal estruturados ou moderadamente estruturados - nas quais nem sempre é evidente e o final da abordagem preventiva e o início da abordagem precaucionária (Barriat e col., 2005).

Em outras palavras, quando houver consideráveis incertezas científicas sobre causalidade, magnitude, probabilidade e natureza do dano, e a ocorrência de cenários graves for plausível, o enfoque da precaução deve ser aplicado. Já a abordagem preventiva deve ser utilizada quando houver uma base confiável para a quantificação de probabilidades, a definição de cenários e a implementação de medidas de controle viáveis. Nessas situações o risco pode ser administrado, sendo possível chegar a um consenso sobre o nível de risco considerado aceitável para uma determinada atividade e estabelecendo medidas para conservá-lo abaixo desse tal nível (World commission on the ethics of scientific knowledge and technology, 2005).

A pesquisa científica com a incorporação da precaução também representa um desafio à saúde coletiva, uma vez que as políticas de saúde geralmente são baseadas na "reação" em vez de na "precaução", ou seja, freqüentemente esperam-se evidências para que se estabeleçam ações. Uma mudança do enfoque da "reação" para "precaução" é inteiramente compatível com os valores centrais da saúde coletiva, pois representaria uma oportunidade de revigorar sua tradição de ação diante da incerteza (Kriebel e Tickner, 2001).

De acordo com Degrassi e colaboradores (2003), o conceito de biossegurança, quando utilizado em relação à introdução e liberação dos organismos geneticamente modificados, inclui a saúde, com todas as suas complexidades e incertezas, uma vez que ela é produto das relações sociais que incorporam uma pluralidade de aspectos que dificultam qualquer certeza a seu respeito. Como se constitui em sistema complexo e incerto, o estudo, a avaliação e o gerenciamento dos riscos à saúde exigem, cada vez mais, a abordagem de outros profissionais, disciplinas e saberes (Palmas e Mattos, 2001). 0 objeto complexo é não-linear, múlti- plo e emergente, alvo de diferentes olhares, fonte de múltiplos discursos. Portanto, para que se consiga abordar essas características, faz-se necessária uma nova modalidade de práxis científica que supere a organização tradicional da ciência, baseada em disciplinas isoladas (Almeida-Filho, 1998).

A abordagem científica dos riscos tende a menosprezar a dimensão social, que é inerente aos riscos e suas análises, pois os riscos à saúde e aos ambientais são processos de construção social, em vez de entidades físicas que existiriam de maneira independente dos seres humanos que os vivenciam e analisam (Cerezo e Luján, 200o). Desta maneira, as características multidimensionais e dinâmicas dos riscos tendem a ser perdidas pelas abordagens descontextualizadas e reducionistas da ciência clássica, baseada na fragmentação disciplinar (Horlick-Jones e Sime, 2004).

Além disso, a controvérsia relacionada à biossegurança é um assunto multifacetado, freqüentemente imerso "em uma confusão de alegações científicas e escolhas políticas que obscurecem as discussões" (Abergel, 200o, p.241). Os principais debates sobre biossegurança freqüentemente estão associados à identificação dos riscos, constituindo-se numa tentativa de reconhecer possíveis efeitos negativos futuros. As controvérsias relacionadas à biossegurança, podem, assim, ser vistas como disputas que abrangem um grupo de questões importantes, com a finalidade da identificação do risco. Portanto, o risco assume claramente um componente normativo, isto é, o julgamento da aceitabilidade de possíveis efeitos e conseqüências (Rasmussen e Borch, 2003).

Exemplo emblemático dessas controvérsias pôde ser observado nas decisões conflitivas em torno da adoção das plantas transgênicas no Brasil. Nesse sentido, Marinho e Minayo-Gomez (2004) destacam que a CTNBio deixou de considerar a importante premissa de que a não comprovação de riscos não implica necessariamente a ausência deles quando emitiu um parecer favorável à liberação da soja transgênica no Brasil. Essa Comissão atestou a ausência de risco ambiental e/ou para saúde humana, sem exigir o Estudo de Impacto Ambiental (EIA) e seu respectivo Relatório de Impacto no Meio Ambiente (RIMA), com a justificativa de que aquele ato constituía-se em um parecer conclusivo, de caráter técnico, elaborado no âmbito da biossegurança. 
No entanto, o parecer técnico da CTNBio parece não ter sido suficiente para a sociedade, resultando em graves suspeitas sobre a referida Comissão quanto à sua isenção e imparcialidade (Telles, 2003). Diversas entidades da sociedade civil organizada recorreram à Justiça e obtiveram decisão judicial favorável à proibição do transgênico aprovado e, em função dessa decisão, decorridos mais de quatro anos após o parecer conclusivo da CTNBio, o plantio não havia se efetivado. Uma grande polêmica foi estabelecida em torno da questão, uma vez que a avaliação da Comissão desconsiderou a complexidade inerente ao assunto, menosprezando interesses dos vários segmentos sociais envolvidos (Victorino, 2004)

A concepção clássica da avaliação de riscos apresenta-se como uma investigação na qual os efeitos adversos específicos podem ser identificados e leis causais conhecidas (probabilísticas ou determinísticas) possam ser aplicadas (Strand, 2001). Contudo, na regulação dos organismos geneticamente modificados enfrenta-se uma situação em que fatos são incertos, com valores em disputa, as decisões são urgentes e a avaliação de riscos da ciência normal torna-se insuficiente (Abergel, 200o). Nesse contexto, considerase pertinente a aplicação dos princípios metodológicos e práticos da ciência pós-normal, uma vez que a situação envolve incerteza, complexidade e indeterminação (Menéndez, 2004; Strand, 2000).

As avaliações de risco não devem ser tecnocráticas, mas ter como base a metodologia mais apropriada. Assim, a estratégia de resolução dos problemas da ciência pós-normal que propõe uma comunidade ampliada de pares, com a conseqüente extensão da discussão aos diferentes atores sociais, o reconhecimento da pluralidade de metodologias, enfoques e valores, constitui um marco teórico mais apropriado para enfrentar os importantes desafios que se apresentam no caso da avaliação e do gerenciamento dos riscos ambientais e à saúde (Menéndez, 2004).

Não se trata de renunciar ao conhecimento científico, e sim considerar a necessidade de que esse conhecimento seja responsável e, sobretudo, baseado na precaução nas situações de maior complexidade. Isso requer o controle social democrático sobre o desenvolvimento científico para impedir que se torne autônomo e inalterável. A incorporação da participação pública em todas as fases do processo de inovação tecnológico e a democratização do complexo ciênciatecnologia são reivindicações inegáveis que a sociedade atualmente coloca (Menéndez, 2004).

Conformar uma ciência direcionada para a saúde coletiva e a sustentabilidade ambiental implica reconhecer como objetivo científico o impulsionar de processos de resolução social dos problemas, incluindo a participação e a aprendizagem mútua entre os diferentes atores sociais envolvidos (Freitas, 2005). É importante destacar que, a participação dos diversos grupos sociais, bem como o reconhecimento e o estímulo às iniciativas comunitárias, representam possibilidades de redefinir relações sociais, que podem contribuir na redução do sofrimento humano, na intensificação da consciência ecológica e na preservação da saúde (Paim e Almeida-Filho, 1998).

Contudo, vale lembrar que muitas das recentes iniciativas que procuram tornar a ciência e a tecnologia mais próximas, transparentes e abertas à participação da sociedade, apesar de seus aspectos louváveis, têm concentrado atenção somente sobre as conseqüências e os riscos (refletindo uma idéia de controle deles). Isso exclui questões mais reflexivas sobre os propósitos humanos e os valores envolvidos nessas situações (Wales e Mythen, 2002; Wynne, 2002; Petersen e Bunton, 2002).

\section{Considerações Finais}

Como demonstrado ao longo deste artigo, o conceito de biossegurança apresenta limitações e implicações, tornando-se necessária a busca de alternativas para iluminar a controvérsia existente sobre esse tema.

A idéia de biossegurança fundamenta-se na premissa de que os riscos ambientais e à saúde podem ser avaliados e controlados de maneira técnico-científica. No entanto, esses riscos são problemas complexos que não podem ser solucionados pelas abordagens reducionistas clássicas da ciência.

A perspectiva da ciência pós-normal apresenta-se, assim, como uma alternativa para a resolução desses problemas, pois destaca as noções de incerteza, complexidade e estimula a resolução dos conflitos por meio da participação e da aprendizagem mútua entre os diversos atores sociais envolvidos.

Além disso, se o objetivo da biossegurança for realmente a proteção da saúde humana e ambiental, tor- 
na-se fundamental a substituição do modelo tradicional tecnocrático de avaliação de riscos, princípio basilar da biossegurança, por uma nova perspectiva que implica uma comunidade ampliada de pares, com a conseqüente extensão da discussão aos diferentes atores sociais e o reconhecimento da pluralidade das metodologias, dos enfoques e dos valores em debate.

Um dos pressupostos da ciência pós-normal, a pesquisa científica com precaução, constitui-se simultaneamente em objetivo e desafio para a saúde coletiva. Isso quer dizer que a incorporação desse enfoque também poderá proporcionar uma oportunidade para o aprimoramento dos processos de tomada de decisão nesse âmbito, pois significará uma mudança do enfoque da "reação" para o da "precaução". o caso do amianto é exemplar nesse sentido: nas primeiras décadas do século XX vários indicadores apontavam para o perigo do uso desse material, mas a inexistência de provas científicas de suas características cancerígenas foi o argumento adotado para sua ampla difusão. O uso da precaução nesse período teria impedido a ocorrência de milhares de mortes que ainda hoje ocorrem devido à exposição a esse agente cancerígeno em vários países, sendo que em diversos, como o Brasil, o seu banimento ainda não ocorreu.

Conceber a noção de biossegurança à luz da ciência pós-normal implica modificação fundamental, principalmente em relação à saúde coletiva: a substituição do discurso tecnicista onipotente por um diálogo entre os diversos atores sociais envolvidos nas questões ambientais e de saúde.

\section{Referências}

ABERGEL, E. Biosafety assessment: artificial controversies? Science as Culture, London, v. 9, n. 2, p. 241-247, jun. 2000.

ALMEIDA-FILHO, N. Sobre as relações entre complexidade e transdisciplinaridade em saúde.

Revista Brasileira de Educação Médica, Rio de Janeiro, v. 22, n. 2/3, p. 22-30, 1998.

ALTHAUS, C. E. A disciplinary perspective on the epistemological status of risk. Risk Analysis, Virginia, v. 25, n. 3, p. 567-588, jun. 2005.
BARRIAT, V. A. et al. Science and precaution in interactive risk evaluation. Brussels: Belgian Science Policy, 2005. Disponível em: <http:// www.belspo.be/belspo/home/publ/pub_ostc/OA/ rOAo1_en.pdf $>$. Acesso em: 27 abr. 2006.

BERG, P. et al. Asilomar conference on recombinant DNA molecules. Science, Washington, v. 188, n. 4192, p. 991-994, 1975 .

BORCH, K.; RASMUSSEN, B. Refining the debate on GM crops using technological foresight: the Danish experience. Technological Forecasting \& Social Change, Rotterdam, v. 72, n. 5, p. 549-566, jun. 2005.

CARDOSO, T. A. O. et al. Memories of biosafety in Brazil: lessons to be learned. Applied Biosafety, Illinois, v. 10, n. 3, p. 160-168, 2005.

CEREZO, J. A. L; LUJÁN, J. L. Ciencia y política del riesgo. Madrid: Alianza Editorial, 2000.

CLARK, N.; STOKES, K.; MUGABE, J. Biotechnology and development: threats and promises for the 21st century. Futures, Rotterdam, v. 34, n. 9/10, p. 7858o6, nov./dez. 2002.

DE MARCHI, B.; FUNTOCOWICZ, S. La gobernabilidad del riesgo en la Unión Europea. In: LUJÁN, J. L.; ECHEVERRÍA, J. Gobernar los riesgos: ciencia y valores en la sociedad del riesgo. Madrid: Ed. Biblioteca Nueva, 2004. p. 153-165.

DEGRASSI, G.; ALEXANDROVA, N.; RIPANDELLI, D. Databases on biotechnology and biosafety of GMOs. Environmental Biosafety Research, Treviso, v. 2, n. 3 , p. 145-16o, jul./set. 2003.

FREITAS, C. M. A produção científica sobre o ambiente na saúde. Cadernos de Saúde Pública, Rio de Janeiro, v. 21, n. 3, p. 679-701, maio/jun. 2005.

FREITAS, C. M. Problemas ambientais, saúde coletiva e ciências sociais. Ciência \& Saúde Coletiva, Rio de Janeiro, v. 8, n. 1, p.137-150, 2003.

FUNTOCOWICZ, S.; RAVETZ, J. Ciência pós-normal e comunidades ampliadas de pares face aos desafios ambientais. História, Ciências, Saúde-Manguinhos, Rio de Janeiro, v. 4, n. 2, p. 219-230, out. 1997.

GALLOPÍN, G. C. et al. J. Science for the twenty-first century: from social contract to the scientific core. International Social Science Journal, Paris, v. 53, n. 168, p. 219-229, jun. 2001. 
GIAMPIETRO, M. The Precautionary Principle and ecological hazards of genetically modified organisms. Ambio, Stockholm, v. 31, n. 6, p. 466-47o, set. 2002.

GLOVER, D. Public participation in national biotechnology policy and biosafety regulation. Brighton: University of Sussex, 2003. (Institute of Development Studies Working Paper, 198).

HILL, R.; JOHNSTON, S.; SENDASHONGA, C. Risk assessment and precaution in the Biosafety Protocol. Review of European Community and International Environmental Law, Oxford, v. 13, n. 3 , p. 263-269, nov. 2004

HORLICK-JONES, T.; SIME, J. Living on the border: knowledge, risk and transdiciplinarity. Futures, Rotterdam, v. 36, n. 4, p. 441-456, maio 2004.

KRIEBEL, D.; TICKNER, J. Reenergizing public health through precaution. American Journal of Public Health, Washington, v. 91, n. 9, p. 1351-1355, set. 2001. KRIMSKY, S. From Asilomar to industrial biotechnology: risks, reductionism and regulation. Science as Culture, London, v. 14, n. 4, p. 309-323, dez. 2005 .

KUHN, T. A estrutura das revoluções científicas. São Paulo: Perspectiva, 1987.

LEVIDOW, L. The GM crops debate: utilitarian bioethics? Capitalism Nature Socialism, London, v. 12, n. 1, p. 44-55, mar. 2001.

MARINHO, C. L. C.; MINAYO-GOMEZ, C. Decisões conflitivas na liberação dos transgênicos no Brasil. São Paulo em Perspectiva, São Paulo, v. 18, n. 3, p. 96102, jul./set. 2004.

MENÉNDEZ, P. G. Las estrategias de resolución de problemas y el estudio científico del riesgo: el caso de los alimentos transgénicos. In: LUJÁN, J. L.; ECHEVERRÍA, J. Gobernar los riesgos: ciencia y valores en la sociedad del riesgo. Madrid: Ed. Biblioteca Nueva, 2004. p. 263-287.

MULLIGAN, S. Biosafety, risk and global knowledge structure. Peace Review, Philadelphia, v. 12, n. 4, p. 571-577, dez. 2000.
PAIM, J. S.; ALMEIDA-FILHO, N. Saúde coletiva: uma 'nova saúde pública' ou campo aberto a novos paradigmas? Revista de Saúde Pública, São Paulo, v. 32, n. 4, p. 299-316, ago. 1998.

PALMAS, A.; MATTOS, U. Contribuições da ciência pós-normal à saúde pública e a questão da vulnerabilidade social. História, Ciências, SaúdeManguinhos, Rio de Janeiro, v. 8, n. 3, p. 567-59o, set./dez. 2001.

PETERSEN, A.; BUNTON, R. The new genetics and public's health. London: Routledge, 2002.

PORTO, M. F. S. Riscos, incertezas e vulnerabilidades: transgênicos e os desafios para a ciência e a governança. Política \& Sociedade, Florianópolis, v. 4, n. 7, p. 77-103, 2005.

PORTO, M. F. S.; ALMEIDA, G. E. S. Significados e limites das estratégias de integração disciplinar: uma reflexão sobre as contribuições da saúde do trabalhador. Ciência \& Saúde Coletiva, Rio de Janeiro, v. 7, n. 2, p. 335-347, 2002.

PORTO, M. F. S; FREITAS, C. M. Análise de riscos tecnológicos ambientais: perspectivas para o campo da saúde do trabalhador. Cadernos de Saúde Pública, Rio de Janeiro, v. 13, p. 59-72, 1997. Suplemento 2.

RASMUSSEN, B.; BORCH, K. Risk and science: are we moving into the fourth age of risk concerns? Risk, Decision \& Policy, London, v. 8, n. 1, p. 1-15, jan./abr. 2003.

RAVETZ, J. R. What is post-normal science. Futures, Rotterdam, v. 31, n. 7, p. 647-653, set. 1999.

RAVETZ, J. The post-normal science of precaution. Futures, Rotterdam, v. 36, n. 3, p. 347-357, abr. 2004.

SANDIN, P. The Precautionary Principle and the concept of precaution. Environmental Values, Isle of Harris, v. 13, n. 4, p. 461-475, nov. 2004

STRAND, R. Naivety in the molecular life sciences. Futures, Rotterdam, v. 32, n. 5, p. 451-470, jun. 2000.

STRAND, R. The role of the risk assessments in the governance of genetically modified organisms in agriculture. Journal of Hazardous Materials, Rotterdam, v. 86, n. 1/3, p. 187-204, set. 2001. 
VICTORINO, V. I. P. Participação pública na construção institucional da biossegurança no Brasil: a questão dos transgênicos. Convergencia Revista de Ciencias Sociales, Toluca, v. 11, n. 35, p.107-127, maio/ ago. 2004 .

WALES, C.; MYTHEN, G. Risky discourses: the politics of GM foods. Environmental Politics, London, v. 11, n. 2, p. 121-144, 2002.

WALKER, W. E. et al. Defining uncertainty: a conceptual basis for uncertainty management in model-based decision support. Integrated

Assessment, Vancouver, v. 4, n. 1, p. 5-17, 2003.

WEED, D. L. Precaution, prevention and public health ethics. Journal of Medicine and Philosophy,

Philadelphia, v. 29, n. 3, p. 313-332, jun. 2004.

WEINER, C. Drawing the line in genetic engineering: self-regulation and public participation. Perspectives in Biology and Medicine, Baltimore, v. 44, n. 2, p. 208 220, 2001.
WORLD COMMISSION ON THE ETHICS OF SCIENTIFIC KNOWLEDGE AND TECHNOLOGY. The Precautionary Principle. Paris: United Nations Educational, Scientific and Cultural Organization, 2005

TELLES, J. L. Bioética, biotecnologias e biossegurança: desafios para o século XXI. In: VALLE, S.; TELLES, J. L. Bioética e biorrisco: abordagem transdisciplinar. Rio de Janeiro: Interciência, 2003. p.171-201.

WYNNE, B. Creating public alienation: expert cultures of risk and ethics on GMOs. Science as Culture, London, v. 10, n. 4, p. 445-481, dez. 2001.

WYNNE, B. Risk and environment as legitimatory discourses of technology: reflexivity inside out? Current Sociology, London, v. 5o, n. 3, p. 459-477, maio 2002. 